\title{
\begin{tabular}{l|l|l} 
Jurnal Kependidikan Dasar & $\begin{array}{l}\text { Volume : } 5 \\
\text { Nomor : } 1 \\
\text { Tahun : } 2020\end{array}$ \\
\hline
\end{tabular}
}

\section{Pengembangan Panduan Praktikum Kimia Dasar 1 dengan Model Learning Cycle}

\author{
Syaiful Arif \\ IAIN Ponorogo \\ Surel: syaiful@iainponorogo.ac.id
}

\begin{abstract}
Abstrak
Pembelajaran praktikum kimia dasar 1 di Jurusan Tadris Ilmu Pengetahuan Alam IAIN Ponorogo menemui beberapa kendala diantaranya belum tersusunnnya panduan praktikum yang menunjang mata kuliah prktikum kimia dasar. Penelitian ini bertujuan untuk mengembangkan penduan prakatikum kimia dasar 1 yang tervalidasi oleh para ahli dibidang kimia dan media. Learning Cycle merupakaan model yang dipilih dalam penelitian ini agar menghasilkan produk panduan praktikum sesui dengan karakter dan keunikan dalam pembelajaran praktikum kimia dasar 1. Penelitian yang dilakukan merupakan penelitian pengembangan, dengan model pengembangan ADDIE yang terdiri dari tahap analysis, tahap design, tahap development, tahap implementation, dan tahap evaluation. Agar mendapatkan produk pengembangan yang baik dilakukan proses validasi ahli isi/materi dan validasi ahli media dan desain pembelajaran. Hasil validasi ahli isi/materi yang dilakukan oleh tiga ahli menunjukkan skor rata rata $90 \%$ sangat memenuhi dan layak untuk digunakan dalam pembelajaran praktikum kimia dasar 1, sedangkan hasil validasi ahli media atau desain pembelajaran yang dilakukan oleh dua orang ahli menunjukkan skor rata-rata 83,14\% memenuhi dan layak digunakan dalam pembelajaran praktikum kimia dasar 1 . Sedangkan pada tahap implementasi skala kecil dilapangan menunjukkan skor 88,50\% yang menunjukkan panduan praktikum kimia dasar 1 yang dikembangkan layak dan mudah dalam penggunaanya.
\end{abstract}

Keywords: pengembangan, validasi, praktikum, ADDIE,

\section{Abstract}

Learning basic chemistry practicum 1 in the Tadris Department of Natural Sciences IAIN Ponorogo encountered several obstacles including the lack of preparation of practical guidelines that supportchemistry practice courses basic. The aim of this study is to develop a guide tochemical practice basic1 which is validated by experts in the field of chemistry and media. Learning Cycle merupakaan model chosen in this study in order to 
produce practical guidelines within their character and uniqueness in learning basic chemistry lab 1 . Research conducted a research development, the ADDIE development model consisting of the analysisphase, designphase,phase, developmentphase implementation, andstage evaluation. In order to get good product development, theexpert validation processvalidation process are carried out content / materialand the media and learning design. The results of theexperts' validation contentconducted by three experts showed an average score of $90 \%$ very fulfilling and suitable for use in learning basic chemistry practicum 1, while the results of the validation of media experts or learning designs conducted by two experts showed an average score of 83, 14\% meet and are suitable for use in learning basic chemistry practicum 1. While in thestage in the small scale implementationfield shows a score of $88.50 \%$ which shows the basic chemistry practicum guide 1 developed is feasible and easy to use.

Keywords: development, validation, practicum, ADDIE,

\section{A. PENDAHULUAN}

Pendidikan adalah usaha sadar dan terencana untuk mewujudkan suasana belajar dan proses pembelajaran agar mahasiswa secara aktif mengembangkan potensi dirinya untuk memiliki kekuatan spiritual keagamaaan, pengendalian diri, kepribadian, kecerdasan, akhlak mulia, serta keterampilan yang diperlukan diri, masyarakat, bangsa, dan negara. ${ }^{1}$ Usaha sadar ini dikelola oleh pemerintah dalam lembaga lembaga pendikan tinggi untuk mengembangkan potensi dan keterampilan mahasiswa. ${ }^{2}$ Pada

1 Rosida Tiurma Manurung, "Pendidikan antikorupsi sebagai satuan pembelajaran berkarakter dan humanistik," Jurnal Sosioteknologi 11, no. 27 (2012): 227-239; Ismail Darimi, "Diagnosis Kesulitan Belajar Siswa Dalam Pembelajaran Aktif di Sekolah," JURNAL EDUKASI: Jurnal Bimbingan Konseling 2, no. 1 (2016): 30-43; Ngalim Purwanto, Ilmu Pendidikan Teoritis dan Praktis (Bandung: PT Remaja Rosdakarya, 2011).

2 Mohammad Ali, Pendidikan untuk pembangunan nasional: menuju bangsa Indonesia yang mandiri pendidikan tinggi menekankan tiga sapek yaitu pengetahuan, sikap dan keterampilan.

Pendidikan yang berorientasikan pada keterampilan adalah pedidikan yang memberi bekal dasar dan latihan secara benar kepada mahasiswa tentang nilainilai kehidupan agar mahasiswa mampu dan terampil dalam menjalankan kehidupannya. Terampil dalam kehidupan dapat diartikan mampu menjaga kelangsungan hidup dan perkembangannya untuk menyelesaikna persoalan persolan kehidupan.

Program Studi Tadris IPA adalah salah satu jurusan dilingkungan Fakultas Tarbiyah dan Keguruan (FATIK) IAIN

dan berdaya saing tinggi (Grasindo, 2009); Siswo Wiratno, "Pelaksanaan pendidikan kewirausahaan di pendidikan tinggi," Jurnal Pendidikan dan Kebudayaan 18, no. 4 (2012): 454466; Nur Kholis, "Paradigma Pendidikan Islam Dalam Undang-undang Sisdiknas 2003," Jurnal Kependidikan 2, no. 1 (2014): 71-85; Manurung, "Pendidikan antikorupsi sebagai satuan pembelajaran berkarakter dan humanistik." 
Ponorogo yang baru berusia dua tahun. Tadris IPA lahir untuk menjawab kebutuhan dunia pendidikan akan tersedianya guru-guru IPA dijenjang MTs/SMP di lingkungan karesidenan Madiun. Di dalam tadris IPA yang berorientasi mencetak calon guru-guru IPA tentunya dibekali berbagai pengetahuan didunia sains misalnya matakuliah fisika dasar, biologi umum, kimia dasar dan lain sebagainya.

Kimia dasar adalah salah satu matakuliah yang wajib ditempuh oleh mahasiswa Tadris IPA. Kimia mengajarkan tentang pengetahuan yang bersifat microscopis dan juga kemampuan laborattoris, kemampuan laboratoris tentunya juga dilaksanakan di laboratorium. Adanya matakuliah praktikum kimia dasar bertujuan untuk memperkuat materi dan penguasaan keterampilan di laboratoium. Berdasarkan hasil wawancara dengan mahasiswa Tadris IPA tanggal 5 Mei 2018 pelaksanan kegiatan praktikum kima masih kurang aplikatif, panduan yang masih sederhana, tidak kontekstual dan sulit memahami prinsip dasar dari laboratorium. Ketersedian buku panduan praktikum yang menunjang secara penuh terhadap pembelajaran kimia dasar memang belum disusun, dampaknya kegiatan labratorium tidak terkonsep matang dan hasil yang diharapkan juga tidak maksimal.

Eksperimen di laboratorium bukan hanya sekedar kegiatan untuk membuktikan atau mencocokkan teori yang telah diberikan di kelas, tetapi mengutamakan proses berpikir ilmiah dengan munculnya pertanyaan- pertanyaan yang terkait dengan materi yang dipelajari. ${ }^{3}$ Kegiatan eksperimen atau percobaan merupakan kegiatan penunjang proses belajar untuk menemukan prinsip atau menjelaskan prinsip-prinsip yang dikembangkan. ${ }^{4}$ Ketersedian panduan praktikum menjadi sesatu yang tidak bisa dipisahkan dari kegiatan laboratorium. Hasil wawancara dengan mahasiswa kegiatan laboratoum dilakukan dengan petunjuk yang belum tersruktur dan belum mencerminkan kegiatan ilmiah.

Salah satu pilihan untuk memperbaiki pelaksanaan matakuliah praktikum kimia dasar satu adalah mengembangkan buku panduan praktikum kimia yang melalui pendekatan saintifik dan ilmiah. Pengembnagan ini perlu direalisasikan guna memenuhi kebutuahan akan pembelajaran dilaboratorium bagi calon guru IPA. Bentuk model pendekatan saintifik dilakukan dengan menggunakan model learning cycle $5 E$ yang dikembangkan oleh Robert Karbles pada tahun 1960 terdiri dari: 5 1. Engagment (motivasi dan membangkitkan minat mahasiswa) 2) Eksploration (menyelidiki) 3) Explanation (menjelaskan)

\footnotetext{
${ }^{3}$ Eko Budi Prasetyo Nugroho, Endang Budiasih, dan Dedek Sukarianingsih, "Pengembangan Buku Petunjuk Praktikum Kimia SMA/MA Kelas X Semester 2 Berbasis Learning Cycle 5E," Atikel Publikasi Universitas Negeri Malang, 2013. ${ }^{4}$ Mulyati Arifin, Strategi Belajar Mengajar Kimia (Malang: Universitas Negeri Malang Press, 2005). 109.

${ }^{5}$ Lorraine V. Aragon, "Copyrighting culture for the nation? Intangible property nationalism and the regional arts of Indonesia," International Journal of Cultural Property 19, no. 3 (2012): 269312.
} 
Elaboration (menerapkan) 6) Evaluation (menilai)

Penelitian terdahulu menunjukkan keuntungan dari penggunaan 5e learning cyle adalah memberikan kesempatan kepada siswa untuk mengaitkan informasi yang baru dengan struktur kognitif yang telah dimilikinya sehingga pembelajaran akan lebih bermakna, memberikan peluang kepada siswa untuk melatih sikap ilmiah siswa. ${ }^{6}$ Learning cycle $5 E$ memperkaya pembelajaran dan memberi pengalaman saintifik yg lebih nyata. ${ }^{7}$ Penelitian tersebut memerikan gambaran penting model learning cycle adalah alternatif untuk memberikan pengalaman bagi mahasiswa, dan pembelajaran lebihbermakna di laboratorium.

\section{B. METODE PENELITIAN}

Penelitian yang dilakukan termasuk penelitian pengembangan atau sering disebut dengan Research and Development ( $\mathrm{R} \quad \& \quad \mathrm{D})$ dengan menggunakan model ADDIE yang dimodifikasi dan disesuaikan dengan kebutuhan peneliti, tahapan ADDIE yang terdiri dari lima langkah yaitu Analysis, Design, Development, Implementation dan Evaluation. ${ }^{8}$ Penelitian berfokus pada

${ }^{6} \mathrm{R}$ Melani dan \& Sugiharto Harlita B, "Pengaruh Metode Guided Discovery Learning terhadap Sikap Ilmiah dan Hasil Belajar Kognitif Biologi Siswa SMA Negeri 7 Surakarta Tahun Pelajaran 2011/2012," Jurnal Pendidikan Biologi 4 No 1 (t.t.): 97-105.

${ }^{7}$ Hakan Turkmen, What Technology Plays Supporting Role in Learning Cycle Approach for Science Education (TOJET, 2006).

8Selay Arkun dan Buket Akkoyunlu, "A Study on the Development Process of a Multimedia Learning Environment According to the ADDIE pengembangan panduan praktikum kimia dasar 1 dengan model learning cycle 5E

\section{Analysis}

Tahap ini bertujuan untuk mengangkat masalah dasar yang perlu dikembangkan dalam pengembangan panduan praktikum kimia dasar 1, masalah yang dihadapi dalam penelitian ini adalah memang belum tersedianya buku petunjuk praktikum kimia dasar I, karena di IAIN ponorogo praktikum merupakan matakuliah tersendiri dan terasuk dalam prodi baru tahun 2016 baru berdiri sehingga kelengkapan sarana maupun kegitan penunang belum ada. Oleh karena itu dalam penelitian ini kami mengembangkan panduan praktikum kimia dasar I yang tervalidasi. Maka sebagai solusinya perlu dikembangkan panduan praktikum kimia dasar I untuk menunjang pelaksanaan perkuliahan.

2. Design

Tahap desain dilakukan untuk merancang panduan praktikum kimia dasar 1, tahap ini peneliti melakukan dalam bentuk, perumusan tujuan pengembangan panduan praktikum kimia dasar I, perumusan materi praktikum kimia dasar 1, rancangan awal panduan praktikum kimia dasar 1

\section{Development}

Pada tahap ini berujuan untuk menghasilkan panduan praktikum kimia dasar 1, dengan melakukan perbaikan pada rancangan awal atau

Model and Students' Opinions of the Multimedia Learning Environment," IEMJournal, 2008, 1-19. 
modivikasi berdasarkan masukan dan saran dari validator, diperolehlah panduan praktikum kimia dasar I yang tervalidasi.

\section{Implementation}

Pada tahap implementasi dilakukan ujicoba dilapangan terhadap panduan praktikum kimia yang sudah dikembangkan, untuk melihat tangapan mahasiswa yang menggunakan, laboran, serta dosen yang menggunakannya. Tujuan implementasi antara lain membimbing mahasiswa sesuai dengan capaian pembelajaran yang diharapkan, menjamin terjadinya pemecahan masalah bagi mahasiswa yang sedang praktikum.

\section{Evaluation}

Kegiatan evaluasi dilakukan untuk mengetahui apakah panduan praktikum yang dikembangkan dapat membantu proses perkuliahan yang diharapkan. Evaluasi di lakukan dengan memberikan angket kepada mahasiswa yang praktik dengan menggunakan panduan praktikum yang sudah dikembangkan.

Teknik pengambilan data

Pengumpulan data utama untuk mengetahui segi kelayakan panduan praktikum kimia dasar 1 dengan model learning cycle dilakukan dengan cara memvalidasi panduan praktikum yang sudah dikembangkan kepada ahli materi dan ahli desain media untuk memberikan penilaian terhadap produk yang dikembangkan, setiap pertanyaan penilaian yang diajukan memiliki aternatif jawaban sebanyak lima yaitu: 1 (sama sekali kurang baik), 2 ( kurang baik), 3 (cukup baik), 4 (baik), 5 (sangat baik). Yang kemudian sumua jawaban diolah dengan menggunakan rumus:

Persentase $=\frac{\sum(\text { jawaban } x \text { bobot tiap pilihan })}{n \times \text { bobot tertinggi }} \times 100 \%$

Untuk mengetahui kelayakan panduan praktikum yang sudah dikembangkan dapat dianalisis dengan tabel sebagai berikut. ${ }^{9}$

Tabel 1 :Kriteria skala Likert

\begin{tabular}{|l|l|}
\hline Skor & \multicolumn{1}{|c|}{$\begin{array}{c}\text { Kriteria } \\
\text { persepsi }\end{array}$} \\
\hline $0 \%-$ & Sangat tidak \\
$20 \%$ & memenuhi \\
\hline $21 \%-$ & Tidak \\
$40 \%$ & memenuhi \\
\hline $41 \%-$ & Kurang \\
$60 \%$ & memenuhi \\
\hline $61 \%-$ & Memenuhi \\
$80 \%$ & \\
\hline $81 \%-$ & Sangat \\
$100 \%$ & memenuhi \\
\hline
\end{tabular}

\section{HASIL DAN PEMBAHASAN}

Pengembangan panduan praktikum kimia dasar 1 dengan model learing cycle yang dilaksanakan melalui lima tahapan dari pengembangan ADDIE yaitu:

Anlysis: Tahap kegiatan analysis bertujuan untuk menganalisis permasalahan yang muncul dalam pelaksanaan kegiatan pembelajaran pada matakuliah praktikum kimia dasar 1 . Analisis kebutuhan dilakukan untuk menentukan kompetensi yang dibutuhkan mahasiswa (praktikan) dalam

\footnotetext{
9 Riduwan, Skala Pengukuran Variabel Penelitian (Jakarta: Alfa Beta, 2003).
} 
meningkatkan kinerja dan atau prestasi belajarnya. ${ }^{10}$

\section{Analisis terhadap matakuliah praktikum kimia dasar 1 adalah} matakuliah yang berdiri sendiri dengan jumlah SKS yaitu 2, matakuliah ini wajib di tempuh oleh mahasiswa tadris IPA di semester tiga yang tentunya diasuh oleh dosen matakuliah kimia dasar. Dalam pelaksanaan matakuliah ini mahasiswa disyaratkan sudah menempuh dan lulus matakuliah kimia dasar 1 pada semester satu atau matakuliah kimia dasar 2 pada semester 2, sehingga pelaksanaan matakuliah ini dilakukan di semeter 3 .

Hadirnya matakuliah praktikum kimia dasar secara tidak langsung mengajak dosen untuk menyiapkan segala sesuatunya terkait praktikum agar pelaksanaan matakuliah tersebut bisa berjalan dan menyusun rencana kegitan pembelajaran serta melakukan manajemen laboratorium kimia dasar. Prodi tadris IPA di lingkungan IAIN Ponorogo tergolong prodi baru berdiri tahun 2016, kesiapan sarana pendukung dalam kegiatan akademik tentunya menjadi masalah besar yang dihadapi prodi tadris IPA. Sarana kegiatan matakuliah praktikum kimia dasar adalah masalah utama yang harus segera ditangani, sarana yang dimaksud adalah laboratorium kimia dasar.

Laboratorium kimia dasar yang dimiliki oleh prodi tadris IPA merupakan laboratorium yang memang belum didesain secara baik dan terstandart, dengan segala keterbatasan baik dana maupun sumberdaya manusia, sebuah

10 B. A Pribadi, Model Desain Sistem Pembelajaran (Jakarta, 2011). kelas pembelajaran harus disulap menjadi laboratorium kimia dasar agar mahasiswa tetap bisa melakukan kegiatan praktikum sesuai dangan matakuliah yang sudah diprogramnya. Kegiatan di laboratorium tentunya harus di persiapkan dengan matang oleh dosen pengampu matakuliah bekerjasama denga laboran, salah satu kesiapa tersebut diantaranya adalah dengan adanya panduan praktikum yang tervalidasi oleh para ahli agar mendapatkan panduan praktikum yang sesuai dengan kondisi ideal sebuah buku panduan. Namun dalam hal ini paduan praktikum yang digunakan untuk pelaksanaan pembelajaran praktikum kimia dasar belum memenuhi hal tersebut, oleh karena itu dikembangkan dan dirumuskan panduan praktikum kimia dasar yang tervalidasi oleh para ahli.

\section{Analisis terhadap kemampuan Mahasiswa.}

Tadris IPA IAIN Ponorogo bersal dari berbagai latar belakang yang berbeda, perbedaan ini tentunya berpotensi untuk menghambat pelaksanaan pembelajaran praktikum kimia dasar. Latar belakang yang dimaksud adalah pengalaman belajar yang diperoleh di jenjang MA/SMA/SMK, karena tingkat sarana dan prasarana laboratorium yang dimiliki sekolah berbeda menyebabkan pengalaman belajar yang dimiliki mahasiswa juga berbeda pula, perbedaan ini menjadi penyebab pembelajaran praktikum kimia dasar perlu distandarkan agar dasar dasar keterampilan di laboratorium bisa sama sesuai dengan standart keselamatan. Pengembangan panduan praktikum kimia 
dasar1 menjadikan sarana untuk memberikan pengalaman belajar yang sama dari dasar dasar kemampuan laboratorium yang harus dikuasai mahasiswa.

Analisis terhadap pokok bahasan praktikum kimia dasar 1, dilakukan dengan cara merinci materi pokok apa saja yang digunakan untuk praktikum kimia dasar 1 sesuai dengan target dan sasaran yang ditentukan, adapun materi pokok kegiatan praktikum kimia dasar 1sebagai berikut: 1) Pengenalan Alat dan Bahan 2) Keterampilan Penggunaan Alat, 3) Perubahan Materi, 4) Pengukuran di Laboratorium, 5) Pemisahan Campuran, 6) Pembuatan Larutan, 7) Asam dan Basa, 8) Struktur Lewis dan Model Molekul, 9) Reaksi-reaksi Kimia, 10) Destilasi sederhana.

Desain: tahap kegiatan desain bertujuan untuk membuat desain awal panduan praktikum kimia dasar 1 dengan model learning cycle 5E, dan menetapkan kegiatan praktikum yang akan disusun dalam panduan praktikum. Adapu format awal paduan praktikum sebagaiberikut: Caver depan, Pengantar, kemudian bagian isi masing-masing percobaan yaitu a) Judul praktikum, b) Tujuan praktikum, c) Fase Engagment, d) Fase Eksploration, e) Fase Eksplanation, f) Fase Elaboration , g) Fase Evaluation.

\section{Development:}

Tahap

pengembangan (development) merupakan tahapan terpenting dalam kegiatan penelitian ini, tujuan dari tahapan ini adalah mengembangkan panduan praktikum kimia dasar 1 yang sudah direncanakan sesuai dengan format agar menjadi panduan praktikum kimia dasar
1. Supaya panduan praktikum yang dikembangkan menjadi produk yang bagus tentunya harus mendapatkan perbaikan dan masukan dari beberapa pakar. Adapun pakar yang dilibatkan dalam penelitian pengembangan ini adalah ahli isi/materi yaitu dosen kimia dan dosen IPA, bertugas melakukan validasi terhadap produk yang dikembangkan dari segi isi atau materi, dan ahli desain/media yaitu dosen teknologi pendidikan, bertugas melakukan validasi terhadap desain produk yang sudah dikembangkan, berdasarkan tampilan, ukuran pewarnaan, model tulisan dan lain sebagainya. Berdasarkan masukan, saran dan penilaian dari para pakar peneliti melaksanakan perbaikan dan revisi agar mengahasilkan suatu draf panduan prakatikum yang tervalidasi oleh para ahli.

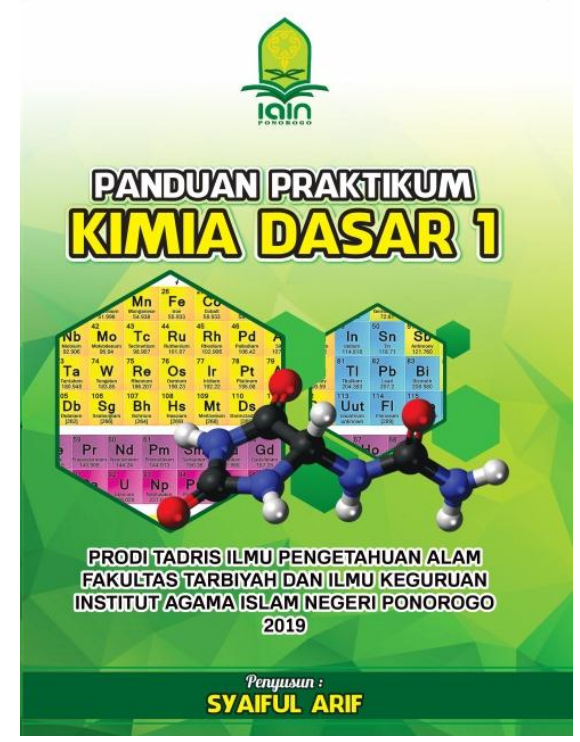

Gambar 1. Sampul depan panduan praktikum kimia dasar 1 
GRAFIK HASIL VALIDASI AHLI ISI ATAU MATERI

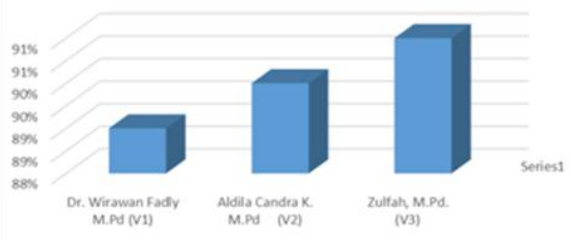

Gambar 1 persentase hasil validasi ahli isi/materi

Hasil validasi yang dilakukan oleh dosen kimia dan dosen IPA sebagai validator ahli isi dan materi dalam pengembangan panduan praktikum kimia dasar 1 yang sudah dikembangkan sebagai berikut:

Berdasarkan gambar grafik di atas rekapitulasi perolehan nilai validasi ahli isi atau materi terhadap produk panduan praktikum kimia dasar 1 nilai rata-rata menunjukkan $90 \%$, yang artinya panduan praktikum kimia dasar 1 kategori sangat memenuhi dan layak untuk digunakan dalam kegiatan laboratorium kimia.

Hasil validasi yang dilakukan oleh dosen teknologi pendidikan atau pembelajaran sebagai validator media atau desain dalam pengembangan panduan praktikum kimia dasar 1 yang sudah dikembangkan sebagai berikut:

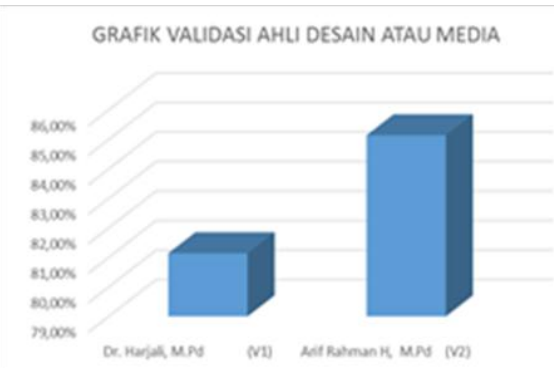

Gambar 2 persentase hasil validasi ahli media atau desain pembelajaran
Berdasarkan rekapitulasi perolehan nilai validasi ahli media atau desain terhadap produk panduan praktikum kimia dasar 1 nilai rata-rata menunjukkan 83,14 \% yang artinya panduan praktikum kimia dasar 1 kategori sangat memenuhi dan layak untuk digunakan dalam kegiatan laboratorium kimia.

Implementation: Produk panduan praktikum kimia dasar 1 yang sudah divalidasi oleh para ahli dan pakar, selanjutnya kemudian dilakukan implementasi atau ujicoba pada suatu kelas yang terbatas. Ujicoba yang peneliti lakukan berlangsung di laboratorium kimia dasar prodi tadris IPA IAIN Ponorogo dengan jumlah peserta 16 mahasiswa, jumlah tersebut di sesuaikan dengan kapasitas ruang laboratorium yang memang tidak bisa menampung dalam jumlah banyak mahasiswa. Tujuan pelaksanaan kegiatan implementasi diantaranya adalah: a) untuk mengukur kefektifan penggunaan produk yang dikembangkan jika digunakan dilapangan yang sebenarnya b) mendapatkan masukan dan saran terkait produk yang dikembangkan oleh pengguna sehingga bisa dilakukan perbaikan terhadap produk c) mengetahui berbagi kesulitan yang dihadapi pengguna ketika menggunakan produk yang sudah dikembangkan, dengan demikian peneliti bisa mencari solusi dari permasalahan tersebut. 


\section{GRAFIK ANGKET RESPON MAHASISWA}

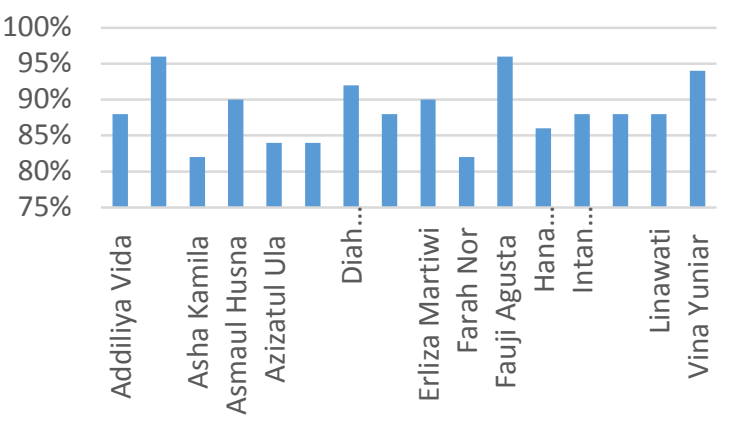

Gambar 3. Presentasi hasil angket respon mahasiswa terhadap penggunaan panduan praktikum kimia dasar 1 yang dikembangkan

Perolehan angket respon mahasiswa menunjukkan angka rata-rata 88,50 \% yang menunjukkan produk yang dikembangkan mudah digunakan, dan relevan untuk digunakan oleh mahasiswa dalam praktikum.

Evaluation: Tahap terakhir dari pengembangan produk panduan praktikum kimia dasar 1 adalah evaluasi. Kegiatan evaluasi dilakukan untuk menyempurnakan produk yang sudah di revisi dan melihat kembali proses pengembangan yang dilakukan sudah sesuai dengan tahapan yang dilakukan atau belum. Pelaksanaan evaluasi peneliti lakukan dengan cara membuat Focus Group Discussion (FGD) dengan validator ahli dan pengguna dalam hal ini mahasiswa setelah menggunakan produk yang sudah dikembangkan. Tujuan utama dari kegiatan evaluasi adalah melihat secara keseluruhan terhadap produk yang dikembangkan dan memastikan semua masukan dari validator atau pengguna bisa dimanfaatkan untuk perbaikan produk sehingga diperoleh produk final panduan praktikum kimia dasar 1 .

\section{KESIMPULAN}

Pengembangan panduan praktikum kimia dasar 1 dengan model Learning Cycle 5E yang sudah dikembangkan melalui tahapan analysis, desain, development, implementation dan evaluation dapat disimpulkan. Produk panduan praktikum kimia dasar 1 dengan model learning cyle layak munurut ahli isi atau materi dengan prosentase rata-rata 90\%. Produk panduan praktikum kimia dasar 1 dengn model learning cyle layak munurut ahli media atau desain pembelajaran dengan prosentase rata-rata $83,14 \%$. Ujicoba terbatas menunjukkan respon yang memenuhi dengan prosentase perolehan $88,50 \%$ oleh mahasiswa.

\section{E. DAFTAR PUSTAKA}

Ali, Mohammad. Pendidikan untuk pembangunan nasional: menuju bangsa Indonesia yang mandiri dan berdaya saing tinggi. Grasindo, 2009.

Aragon, Lorraine V. “Copyrighting culture for the nation? Intangible property nationalism and the regional arts of Indonesia." International Journal of Cultural Property 19, no. 3 (2012): 269-312.

Arifin, Mulyati. Strategi Belajar Mengajar Kimia. Malang: Universitas Negeri Malang Press, 2005.

Arkun, Selay, dan Buket Akkoyunlu. "A Study on the Development Process of a Multimedia Learning Environment According to the 
ADDIE Model and Students' Opinions of the Multimedia Learning Environment." IEMJournal, 2008, 1-19.

Darimi, Ismail. "Diagnosis Kesulitan Belajar Siswa Dalam Pembelajaran Aktif di Sekolah." JURNAL EDUKASI: Jurnal Bimbingan Konseling 2, no. 1 (2016): 30-43.

Kholis, Nur. "Paradigma Pendidikan Islam Dalam Undang-undang Sisdiknas 2003." Jurnal Kependidikan 2, no. 1 (2014): 71-85.

Manurung, Rosida Tiurma. "Pendidikan antikorupsi sebagai satuan pembelajaran berkarakter dan humanistik." Jurnal Sosioteknologi 11, no. 27 (2012): 227-239.

Melani, R, dan \& Sugiharto Harlita B. "Pengaruh Metode Guided Discovery Learning terhadap Sikap Ilmiah dan Hasil Belajar Kognitif Biologi Siswa SMA Negeri 7 Surakarta Tahun Pelajaran 2011/2012." Jurnal Pendidikan Biologi 4 No 1 (t.t.): 97-105.

Nugroho, Eko Budi Prasetyo, Endang Budiasih, dan Dedek Sukarianingsih. "Pengembangan Buku Petunjuk Praktikum Kimia SMA/MA Kelas X Semester 2 Berbasis Learning Cycle 5E." Atikel Publikasi Universitas Negeri Malang, 2013.

Pribadi, B. A. odel Desain Sistem Pembelajaran. Jakarta, 2011.

Purwanto, Ngalim. Ilmu Pendidikan Teoritis dan Praktis. Bandung: PT Remaja Rosdakarya, 2011.
Riduwan. Skala Pengukuran Variabel Penelitian. Jakarta: Alfa Beta, 2003.

Turkmen, Hakan. What Technology Plays Supporting Role in Learning Cycle Approach for Science Education. TOJET, 2006.

Wiratno, Siswo. "Pelaksanaan pendidikan kewirausahaan di pendidikan tinggi." Jurnal Pendidikan dan Kebudayaan 18, no. 4 (2012): 454466. 